This item was submitted to Loughborough's Research Repository by the author.

Items in Figshare are protected by copyright, with all rights reserved, unless otherwise indicated.

\title{
Public opinions on alternative lower carbon wall construction techniques for UK housing
}

PLEASE CITE THE PUBLISHED VERSION

http://dx.doi.org/10.1016/j.habitatint.2011.12.015

PUBLISHER

(C) Elsevier

VERSION

AM (Accepted Manuscript)

LICENCE

CC BY-NC-ND 4.0

REPOSITORY RECORD

Hamilton-MacLaren, Fiona, Dennis L. Loveday, and Monjur Mourshed. 2019. "Public Opinions on Alternative Lower Carbon Wall Construction Techniques for UK Housing”. figshare. https://hdl.handle.net/2134/9712. 
This item was submitted to Loughborough's Institutional Repository (https://dspace.lboro.ac.uk/) by the author and is made available under the following Creative Commons Licence conditions.

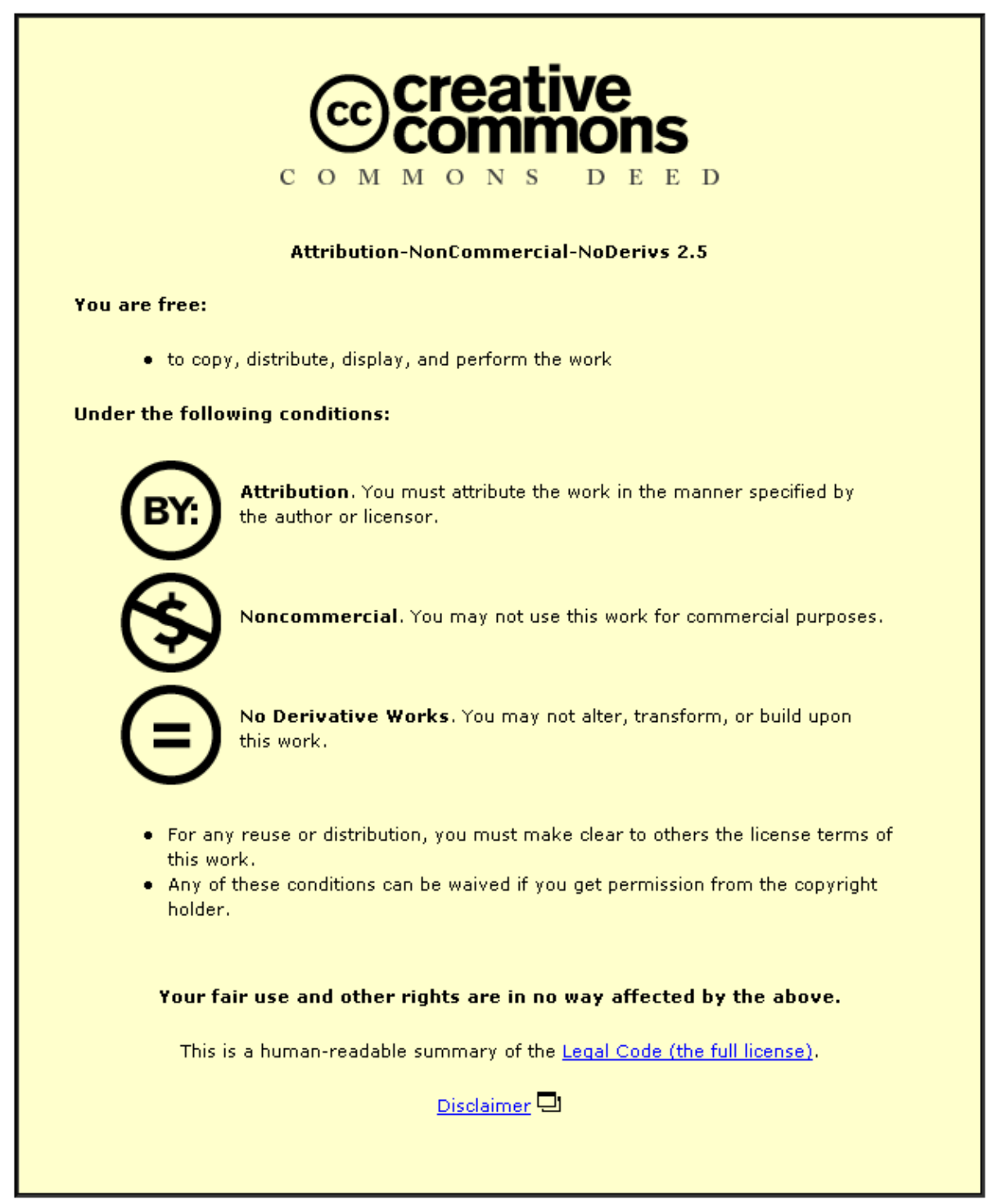

For the full text of this licence, please go to: http://creativecommons.org/licenses/by-nc-nd/2.5/ 


\title{
Public opinions on alternative lower carbon wall construction techniques for UK housing
}

\begin{abstract}
There is a widespread interest in reducing environmental impacts of all industries and processes to help achieve the targets set in the Climate Change Act of 2008. The use of alternative construction techniques to build the walls of UK housing has the potential to reduce their environmental impact in a range of ways. This includes the reduction of embodied energy as well as operational energy use, the latter through improved thermal performance. A major challenge to be overcome if alternative techniques are to be used is the acceptability to purchasers. The current acceptability of a range of construction techniques and issues that are important to purchasers were examined using a questionnaire. Although the acceptability of lower carbon alternatives is less than that of the conventional technique, findings in this research suggest that there is potential for their use in UK housing. The acceptability of alternative construction techniques varies greatly with type. Concerns expressed about the construction techniques could often be dispelled by existing research, indicating that education is key to improving acceptability of alternative construction techniques and hence opening the way to accessing their environmental benefits. The respondents identified environmental issues, finance, operating costs and risk as key areas of concern, which need to be considered during decision-making.
\end{abstract}

Keywords: UK, Sustainability, Housing, Wall, Low carbon construction

\section{Introduction}

\subsection{Background}

A target of $80 \%$ reduction in total UK carbon emissions below 1990 levels by 2050 has been set in the Climate Change Act 2008 (UK Parliament, 2008). Consequently, several policy measures have been adopted for a significant reduction in carbon emissions from UK housing (DCLG, 2008a). Measures for the new-build housing sector include frequent updates to the building regulations, focusing on the reduction of operational carbon emissions to zero by 2016 (DCLG, 2007). As the operational carbon emissions fall to zero, the emissions associated with the construction stage (i.e. the embodied carbon) increases in importance. Ravetz (2008) noted that embodied carbon of newer homes accounted for as much as $27 \%$ of the lifetime carbon emissions. Therefore, the share of embodied carbon will account for a much greater proportion of the carbon emissions associated with zero carbon homes. For any housing where all operational energy requirements are met from zero carbon sources, the embodied carbon will account for $100 \%$ of the lifetime carbon cost.

This work focuses on housing, as it accounts for $27 \%$ of the UK's carbon emissions (Boardman, 2007). By reducing these emissions through a combination of improved new build standards, renovations and alternative methods of energy generation, a significant step would be taken towards achieving the $80 \%$ carbon reduction target. Improving energy use by retrofitting existing buildings has an important part to play; however, it is also important to find ways to construct new buildings so that they contribute to 
the solution from the outset, rather than requiring retrofitting in the near future. Retrofitting is the focus of a number of Government schemes such as the Green Deal (DECC, 2010) so is not considered here. Focus is given to the use of alternative wall construction techniques, which have the potential to improve environmental standards of new-build housing.

Reducing environmental impacts from construction can be achieved in a number of ways: by using low embodied energy materials such as timber (Lenzen \& Treloar, 2002; Gustavsson \& Sathre, 2006); by increasing the use of local materials and thereby reducing the need for transportation (Morel et al., 2001); and by using efficient modern methods of construction such as structural insulted panels (SIPs) and insulating concrete formwork (ICF). SIPs and ICF enable a significant reduction in waste, labour and transportation, resulting in a low embodied energy.

It is essential that while the negative environmental impact of housing construction is reduced, factors such as performance and economic viability are not compromised. Minimum levels of performance are controlled through building regulations. It is the potential impact on customer appeal, and hence the economic viability, which has been investigated in this research. Were individuals to be reluctant to purchase a house constructed using a particular technique, then it would have a reduced or no possibility of adoption by the construction industry, because of low potential for sales and hence a high risk of financial loss. By identifying construction techniques that are acceptable to purchasers, it becomes possible to take advantage of these options. This information could be used to shape government policy so that the acceptable lower impact options are encouraged and hence the negative impact of housing is reduced. Construction firms may also find this information helpful if trying to reduce the negative impacts of their projects whilst maintaining saleability and profits. The investigation also addresses factors that house purchasers consider important. These can be applied to both the construction technique and more generally across housing projects.

This research was limited to techniques used to construct walls. Consideration was only given to their use in housing, as the views collected were intended to show the opinions of house purchasers. The geographical area of study was restricted to the UK, because the research was intended to find information that could be used in the development of national policies for the reduction of environmental impacts from housing construction.

\subsection{Construction techniques and their selection}

The work focused on six construction techniques, all of which are suitable for use in house walls. This was considered sufficient to generate useful comparisons but not to be excessive to consider in detail. The selection criteria were:

- Prior use for housing in the UK;

- Availability of detailed information about the method; and

- Method suitable for use across the UK. 
The construction techniques investigated were:

- Structural insulated panel (SIPs) with a brick cladding;

- Insulating concrete formwork (ICF) with a brick cladding;

- $\quad$ Timber frame with brick cladding;

- $\quad$ Thin joint block work with a brick outer skin;

- Prefabricated straw bale wall units with a lime plaster coating; and

- $\quad$ Brick and block.

Brick and block, the most commonly used construction technique in the UK, was included to act as a baseline for comparison. Housing data for England during 1990-3/2009 (DCLG, 2010a) and Scotland during 1997-2002 (Communities Scotland, 2006) suggest that brick and block was used for 88\% and $69 \%$ of all dwellings constructed in England and Scotland respectively. The second most frequently used housing construction technique is timber frame, used for $7 \%$ and $29 \%$ of dwellings in England and Scotland respectively. Timber frame has a much higher level of use in Scotland. The remaining construction techniques were selected to cover a range of available options including modern methods of construction in the form of SIPs and ICF and one atypical method, straw bale and lime plaster. Thin joint block work was chosen because of its similarity to brick and block construction and the implied probability that its acceptability might be similar to that of brick and block. Brick cladding was selected where possible to maintain a consistent appearance between the options and to demonstrate that houses built using alternative construction techniques could look the same as those built using traditional methods. All construction techniques have been successfully used in the UK and are capable of meeting building regulations.

A number of construction techniques were considered but discarded. Rammed earth construction was considered too unusual for many purchasers and could not be used universally across the UK, because of the variations in site soil. Steel framed buildings were not included because of their similarities with timber framed buildings. Offsite pod construction was discarded as it was considered to not be comparable with the other methods. A range of alternative materials based on source was investigated such as local, recycled and reused materials; these were discarded because their availability varied with location.

\section{Method}

A questionnaire was designed and distributed to investigate potential house purchasers' opinion on construction techniques. Questions were included to identify factors that were important to purchasers when considering a house purchase, in particular, ones that could be affected by the use of alternative construction techniques.

\subsection{Questionnaire design}

Questionnaire design was based on methods discussed by Fink (2006) and Oppenheim (1992). Stages followed were: identifying the questions to be answered; generating questions; testing and altering the 
questions as necessary; distribution of the questionnaire; collection of responses and analysis of data. The questionnaire was aimed at answering the following questions:

- What factors are important to house purchasers when considering a house to buy?

- Are house purchasers aware of the construction techniques being examined?

- Would house purchasers buy a house built using the construction techniques being examined?

- What would increase house purchasers' interest in houses built using alternative construction techniques?

The questionnaire was anonymous, with no identifiable personal data collected in order to improve response rates and minimise ethical issues associated with data protection. The importance of a range of influencing factors was examined by using a Likert scale. Respondents were asked to score the importance of each factor on a scale from 1 (not at all) to 5 (very much).

Awareness was determined by a yes/no option for each construction technique. At this point, no additional information about each technique was provided. The acceptability of each technique was examined by providing a labelled, axonometric view (as shown in Figure 1) and a description. Respondents were asked if they would consider purchasing a house constructed using this technique, with options of yes, no and maybe. This had potential for simplification, which was desirable from the points of view of succinctness of responses and probability of having the questions answered in full. Space was also provided in the form of an optional comments box, allowing respondents to expand on their choice and offer a greater depth. This allowed for comments that were relevant but not bound by specific questions, achieving an interview style response on a larger scale than would have been possible to carry out in person.

Pros and cons for each option were not included as the aim was to find out the level of acceptability based on current knowledge. This also reduced the length and complexity of the questionnaire, which was considered beneficial in improving the response rate.

The yes/no options presented to identify what would increase the respondents' interest in housing built using alternative techniques were: low prices; low running costs; low environmental impact; and more information. An open-ended question allowed respondents to add comments on other aspects they felt would increase their interest.

The questionnaire was built using online survey software called SurveyMonkey (SurveyMonkey, 2011), which was also used for distribution and response collection. This simplified the process, as responses were stored automatically, saving time and improving accuracy by eliminating the risk of transcription errors.

A small pilot run was used to test the questions and usability of the online system. The pilot indicated that the time taken to complete the survey was acceptable, with most respondents taking ten minutes. As a result of comments received, the images were altered from 2D cross-sections to 3D axonometric views. Some respondents felt they would have liked more information about each technique; however, the aim was to test acceptability based on current levels of knowledge, so this was not acted upon. 
$<$ Figure 1 is about here $>$

\subsection{Survey population and sample}

The population for this survey was the UK public, as any individual has the potential to be a house purchaser at some point. The only limitations were that respondents should be UK residents and aged eighteen or over. The age restriction imposed to avoid ethical issues associated with surveying minors. Also, persons younger than eighteen were perceived to have very limited views on the subject. Based on the mid-year estimate in 2010 (ONS, 2011), the survey population was approximately 48 million. Online survey distribution places a limitation of computer access on the accessible population. However, the penetration of internet in the UK was estimated to be $82.0 \%$ of the population as of March 2011 (IWS, 2011), which was considered an acceptable limitation.

To achieve a confidence level of $95 \%$ with a confidence interval of 5 , the sample size required would have been 384 respondents (Bartlett et al., 2001). This was taken to be the minimum number of respondents acceptable, with a greater number being preferable to increase the accuracy of findings by reducing the confidence interval and to accommodate partial responses.

\subsection{Questionnaire distribution}

A website was designed to provide information about the research and a link to the survey. Care was taken to avoid the use of phrases that could potentially bias the results. The website address was distributed via a number of methods:

- All personal and professional contacts were contacted;

- A link to the survey website was posted in the "Building" magazine forum; and

- The web link was included in messages to Loughborough University alumni and staff.

Respondents were asked to pass the questionnaire link on to others, to further increase the spread of respondents. This method can also be considered to have influenced a greater coverage of the population via the postulation in the six degrees of separation or small-world theory. The theory suggests that everyone is on average approximately six steps away, by way of introduction, from another person on Earth; i.e. any two individuals can be connected by no more than six others (Schnettler, 2009).

This method of distribution does have the potential to create bias due to the self-selected nature of the respondents. Those who respond are most likely to be interested in the topic or to hold strong views on the issues. To reduce the impact of self-selection on the results the target sample size was increased to 500. Distribution was carried out using the widest range of methods available to encourage a range of respondents; those that passed the survey forward enabled further access to their sections of society. Questions such as age band of respondent were included to allow a post-survey comparison between the distribution of the respondents and the UK population. Income level was not included as it was felt this would greatly reduce response rates. If figures indicated a significant difference between distributions in the survey population and the UK, the larger sample size would have allowed for sampling within the responses. 


\subsection{Response analysis}

The percentage of each response in each category was calculated to identify the most common response. Median and modal scores were calculated for each item related to the issues of importance, enabling a ranking of factors to be created. Exploratory factor analysis was carried out on Likert scores to divide the items into categories about which respondents were concerned. Open-ended questions were individually coded by topic, with an indication whether the comment expressed a positive or negative view. From this, perceived benefits and concerns about each construction technique could be seen, together with the most common views for each. Where a need for more information was expressed, it was labelled as a negative term, as it was considered to express concern about that particular element; e.g. "How does this perform in fire?" would be labelled as a negative comment as the respondent was indicating a concern about flammability.

\section{Results and discussion}

572 responses to the survey were received. Respondents' age distribution was considered to be of particular importance. A high response rate from the youngest or oldest age bands would be unlikely to give a representative view as the average age of mortgage borrowers in 2010 was 39 (DCLG, 2010b). The percentage age distribution for the respondents and the UK are given in Table 1. To confirm that the difference between the UK distribution and the respondents distribution was not significant a Chi squared test was carried out, giving values of $\chi^{2}=8.29$; and $\chi_{0.95}^{2}=9.49$. Respondents from age ranges 30-44 and 45-59 accounted for 35\% and 29\% of the total responses respectively, approximately 5 percentage points higher in each age range than the national distribution. This skewness in the distribution is fairly representative of house purchasing population in the UK. In 2010, people aged between 25 and 44 accounted for $67.8 \%$ of mortgage approvals (DCLG, 2010b), a significant indicator of the characteristics of house purchasing population.

$<$ Table 1 is about here $>$

\subsection{Importance of factors in housing decisions}

The importance to house purchasers of factors such as price and operational energy use could have a significant impact on the feasibility of a construction technique in reducing carbon emissions. If a particular technique is expensive but performs very well thermally, purchasers may reject it if price is their primary concern. They may accept it if energy use rates more highly.

The most important factor to a purchaser when selecting a house was price. $95 \%$ of the respondents rated this as 4 (quite a bit) or 5 (very much). Cheaper construction technique such as those with a faster build time or cheaper materials could increase a technique's appeal to purchasers. However, price is also affected by factors such as location and the economic situation of the region or country.

The need for maintenance was scored as second most important factor. Maintenance requirements vary significantly among the investigated construction techniques. Respondents appear to be aware of the differences to some extent. Therefore, the desire for low maintenance options is likely to be an important consideration. 
Mortgage availability was of importance to $63 \%$ of respondents and was of little concern to $24 \%$. However, mortgage availability is not solely affected by the construction of a house. Purchasers' personal circumstances such as income, savings and outgoings, and the overall economic environment have a role to play. This may be a reflection of respondents' views of the current financial market. On the other hand, the construction technique can impact the availability of mortgages. It is possible to obtain a mortgage for all six; however, the use of specialist firms may be required for alternative techniques, which may affect the price because of limited competition.

Low energy use was scored 4 (quite a bit) or 5 (very much) by $56 \%$ and 3 (some) by $32 \%$. This may be a result of the financial benefits of using less energy and of the increasing awareness of environmental issues.

Fire performance was of less concern to respondents, with $31 \%$ scoring 1 (not at all) or 2 (a little). A further $31 \%$ of the respondents scored 3 (some), indicating a neutral attitude. Only $38 \%$ scored 4 (quite a bit) or 5 (very much), showing a higher level of concern. The fire performance of construction materials and techniques is closely controlled through building regulations. Lower scores on fire performance may imply that the respondents were confident about the role of building regulations in ensuring appropriate fire standards. All investigated construction techniques have been shown to pass relevant fire regulations.

Insurance availability was considered the least important of the factors examined by the respondents. As with mortgages, it is possible to obtain insurance for all six but the use of specialist firms may be needed for alternative techniques.

The modal and median values for each factor are given in Table 2.

$<$ Table 2 is about here $>$

A principal component analysis (PCA) was carried out on the seven sets of Likert scale data using orthogonal rotation, varimax. The Kaiser-Mayer-Olkin (KMO) measure of 0.648 was considered acceptable (Field, 2009) and all KMO values were above the required limit of 0.5 . The correlation of items was tested using Bartlett's test of sphericity, giving a value of $\chi^{2}(253)=663.092, p<.001$, demonstrating their suitability for the analysis. Eigenvalues for each element of the data were calculated, two of which had eigenvalues greater than 1, which would satisfy Kaiser's criterion. However, it was decided to use Joliffe's criterion of factors with eigenvalues above 0.7 being retained, which resulted in four factors. The use of four factors accounts for $77.998 \%$ of the variance. The rotated factor loadings are shown in Table 3. The PCA result suggests that components 1, 2, 3 and 4 represent environmental, financial, operating costs and risk related aspects, respectively. These dimensions should be considered when making decisions about housing.

$<$ Table 3 is about here $>$

\subsection{Awareness of alternative construction techniques}

Percentages of responses on awareness are shown in Figure 2. There is a high level of awareness of brick and block, reflecting its status as the most commonly used housing construction technique. 
Timber framed construction, the second most common technique, also had a high level of awareness. The awareness of alternative techniques is much lower, with the exception of straw bale.

$<$ Figure 2 is about here $>$

\subsection{Acceptability of materials}

\subsubsection{Brick and block}

The acceptability of brick and block construction was very high, with $90 \%$ of respondents saying they would purchase a house built using this method, $8 \%$ saying maybe and $2 \%$ saying no. The most common comment relating to this construction was that it was typical and proven housing construction technique. Factors such as insulation, strength and durability received positive comments. Negative comments were related to a few respondents' dislike of brick and block as an exterior material.

\subsubsection{Structural Insulated Panels (SIPs)}

SIPs had a much lower percentage (57\%) of yes responses than brick and block. However, the rate of maybe answers was higher at 33\%. These combined values indicate that SIPs are likely to be an acceptable construction option if concerns raised by the maybe respondents are addressed. Positive comments were mostly related to the presence of insulation. Appearance of the construction, including the fact that it "looks the same as brick and block" was presented as a positive point by a number of respondents.

The most frequently expressed concern was related to the strength of the construction technique. SIPs are noted to outperform timber framed structures by Hairstans \& Kermani (2007) and Morley (2000). Durability and the effect of moisture on the wood element of the construction were also stated as an issue. The lack of long-term evidence for durability is noted by the DCLG (2008b). Current assessment of durability is based on anecdotal evidence, largely from the USA. Cathcart (1998) and Morley (2000) both cited examples of early buildings constructed with SIPs in the 1950s that were still occupied. Hairstans \& Kermani (2007), on the other hand, based their assessment on more recent examples, considering cases over 30 years old as a convincing argument for durability. Some respondents expressed concerns about the fire performance of SIPs. The concern that the components of SIPs are susceptible to fire has also been noted by Calkins (2009) and Barista (2008). However, Bregulla \& Enjily (2004) suggested that the use of a plasterboard lining enabled UK building regulations to be met.

\subsubsection{Insulating Concrete Formwork (ICF)}

Acceptability levels for ICF were similar to those for SIPs, with a slightly higher rate of maybe responses; $57 \%$ responded yes, 34\% maybe and 9\% no. The main area of concern was the use of large quantities of concrete and the perceived negative environmental impacts of its production. It is possible to reduce this by using fly ash (Calkins, 2009; Johnston \& Gibson, 2008) and recycled aggregates (Calkins, 2009; Anink et al., 1996). The thickness of the wall and the resulting reduction in room sizes were noted as a disadvantage of this technique. A number of respondents felt that ICF would be more expensive than traditional techniques. The view is also expressed in literature (Al-Homoud, 2005; Denzer \& Hedges, 2007). The additional capital cost may be balanced against the performance benefits over the lifecycle of a building. However, further research needs to be conducted to investigate the 
overall economic viability of ICF construction. The level of insulation and strength were seen as benefits of ICF. The similarity of ICF's appearance with conventional construction was also noted as a positive aspect. Like SIPs, ICF has potential to be an acceptable form of housing construction, if minor concerns raised by the respondents are addressed.

\subsubsection{Straw bale with lime plaster}

This option had the lowest acceptability, with 29\% yes, 32\% maybe and 39\% no, indicating a low potential for use. The aspect of greatest concern to respondents was fire performance. Testing discussed by Jones (2007) shows that plastered bales have a resistance of at least 2 hours 40 minutes under standard construction material fire tests of up to $1000^{\circ} \mathrm{C}$, which meets UK building regulations. Durability, in particular rotting, was frequently listed as a reason for low acceptance. Seyfang (2010) and Smith (2007) cited a number of straw bale buildings in use in the USA, constructed between 50 and 100 years before. UK based evidence has a shorter timeframe. Jones (2007) states buildings in the UK constructed in 1994 are still in good condition. Moisture has the potential to result in straw degradation, as discussed by Carfrae et al. (2009) and CMHC (2000). Careful workmanship is essential to avoid water entry so that moisture values remain at safe levels (CMHC, 2000). Straw bale construction was perceived by respondents as having low strength. The load carrying potential of plastered bales has been examined by the CMHC (2008) who concluded that even fairly low quality bales were able to carry sufficient load for use in construction.

Financial problems such as difficulty in obtaining mortgages and insurance were identified as issues. It is possible to obtain mortgage and insurance for this type of structure but only through specialist providers, which greatly reduces its feasibility in mainstream house building. Maintenance was expressed as a concern, an unavoidable factor of straw bale construction, which may reduce its appeal. Low environmental impact and good insulation were identified as positive aspects of straw bale. Opinion was divided on appearance; therefore, a range of external detailing could be used to increase the appeal.

\subsubsection{Thin joint block work}

The responses for this method were $75 \%$ yes, $21 \%$ maybe and $5 \%$ no, representing the second highest acceptability. A high number of respondents noted the similarity between this technique and brick and block, which is likely to be the cause for its high acceptability. In common with comments regarding brick and block construction, respondents expressed a dislike of concrete and its environmental impacts, which can be reduced by using fly ash and recycled aggregates (Calkins, 2009). Positive points noted were the amount of insulation; appearance; strength; and that it was a proven system.

\subsubsection{Timber frame}

Timber frame achieved a lower acceptability than other options except straw bale with lime plaster. $55 \%$ said yes they would buy, $32 \%$ said maybe and $14 \%$ said no. Durability was of concern to respondents, in particular the risk of rotting. Hutton et al. (1992) discussed methods to minimise the rotting of timber in housing by ensuring quality construction to avoid the conditions in which decay occurred. The impact of fire was identified as an issue. Lennon et al. (2000) discussed fire performance 
of medium rise timber frame buildings, concluding that the construction could meet the necessary regulations. However, they noted that a high level of workmanship was required to ensure adequate fire performance. The quality of workmanship is particularly important with this type of construction. It may be necessary to assure the purchaser of construction quality if adoption is to be increased. The presence of insulation, strength and appearance of the finished building were viewed as advantages by the respondents.

\subsection{Increasing interest in alternative construction techniques}

Respondents were presented with four factors as having the potential to increase their interest in alternative housing construction and were asked to give their views.

$99 \%$ of the respondents said that low running costs would increase their interest. This was also reflected in the comments about individual construction techniques. A number of respondents made the association between the level of insulation and operating costs. More information was seen as important both in the yes/no selection and in the comments across the questionnaire. $90 \%$ of the respondents said more information would increase their interest in a particular construction technique. $89 \%$ of the respondents said that low prices would increase their interest. Financial concerns were expressed by the respondents throughout the questionnaire, in particular for the alternative construction options. $86 \%$ of the respondents indicated that a low environmental impact would increase their interest in housing built using alternative construction techniques.

A wide range of other factors was stated as important in the open-ended question. Many of them can be related to the need for more information. A few respondents felt that some form of guarantee attached to the building would increase the appeal. The presence of guarantees may make mortgages and insurance easier to obtain.

\section{Conclusions}

The potential exists for alternative construction techniques to be used in UK housing and, therefore, help achieve better environmental standards. For many of the respondents, a brick finish is indicated as desirable or acceptable. The presence of insulation was frequently noted as a positive aspect of the construction methods.

Responses to the survey indicated a level of acceptability for all investigated alternative techniques, albeit with varying degrees. The highest yes response for an alternative technique was $75 \%$, for thin joint block work. The lowest was 29\%, for straw bale and lime plaster. The yes responses of SIPs and ICF were higher than expected, both at $57 \%$, indicating high acceptability and a high potential for use. The yes responses for timber frame was lower than expected at $32 \%$.

Education is key to increasing the use of alternative construction techniques. Greater awareness of the techniques and their benefits is required to encourage potential house buyers to consider available options rather than choosing with what they are already familiar. This finding is supported by the responses to the open ended questions where maybe responses were often accompanied by further 
questions from respondents. If all maybe responses could be converted to yes responses they would range from ICF with $91 \%$ to straw bale and lime plaster with $61 \%$.

The exploratory factor analysis of the responses identified four focus areas: environmental impact, finance, operating costs and risk. These need to be considered when making construction decisions as they have the potential to affect desirability. The role of finance is of particular interest as it was commented on frequently by the respondents. Government or industry support in this area, in particular in the form of guarantees, may allay financial concerns, and increase the uptake of alternative techniques.

Among the investigated construction techniques, thin joint block work, ICF and SIPs are likely to be the most feasible options for improving environmental performance of houses while maintaining a certain level of saleability due to their high acceptability. Timber frame and straw bale have a greater potential for reducing embodied energy. However, their significantly lower levels of acceptability, as found in this research, would mean that they are less suited to large scale speculative construction.

\section{References}

Al-Homoud, M. (2005). Performance characteristics and practical applications of common building thermal insulation materials. Building and Environment, 40, 352-366.

Anink, D., Boonstra, C., \& Mak, J. (1996). Handbook of sustainable building. London, UK: James \& James (Science Publishers) Ltd.

Barista, D. (2008). Building tight with SIPs. Building Design \& Construction, 49.

Bartlett, J., Kotrlik, J., \& Higgins, C. (2001). Organizational research: Determining appropriate sample size in survey research. Information Technology, Learning and Performance Journal, 19, 43-50.

Boardman, B. (2007). Home truths: A low carbon strategy to reduce UK housing emissions by $80 \%$ by 2050. Oxford, UK: Environmental Change Institute.

Bregulla, J., \& Enjily, V. (2004). An introduction to building with Structural Insulated Panels (SIPs). Watford, UK: BRE Press.

Calkins, M. (2009). Materials for sustainable sites. Hoboken, NJ: John Wiley \& Sons, Inc.

Carfrae, J., DeWilde, P., Littlewood, J., Goodhew, S., \& Walker, P. (2009). Long term evaluation of the performance of a straw bale house built in a temperate maritime climate. In Proceedings of the 11th International Conference on Non-conventional Materials and Technologies (NOCMAT 2009). Bath, UK.

Cathcart, C. (1998). SIPs, not studs. Architecture, 87, 148-152.

CMHC (2000). Straw Bale House Moisture Research. Ottawa, Canada: CMHC.

CMHC (2008). Effect of Mesh and Bale Orientation on the Strength of Straw Bale Walls. Ottawa, Canada: CMHC.

Communities Scotland (2006). Scottish housing condition survey 2002: National report. Edinburgh, UK: Communities Scotland.

DCLG (2007). Building a Greener Future: Towards Zero Carbon Development. London, UK: DCLG.

DCLG (2008a). Definition of zero carbon homes and non-domestic buildings. London, UK: DCLG.

DCLG (2008b). Innovative Construction Products and Techniques. London, UK: DCLG.

DCLG (2010a). English Housing Survey: Housing Stock Report 2008. London, UK: DCLG.

DCLG (2010b). Table 537: Distribution of borrowers' ages, by new/other dwellings and type of buyer. http:/www.communities.gov.uk/housing/housingresearch/housingstatistics/. 
DECC (2010). Green Deal: A summary of the Government proposals. London, UK: DECC.

Denzer, A., \& Hedges, K. (2007). Sustainable construction in Yellowstone Park: A case study. In Proceedings of Sustainable Construction Materials and Technologies Conference. Coventry, UK.

Field, A. (2009). Discovering statistics using SPSS. (3rd ed.). London, UK: Sage Publications Ltd.

Fink, A. (2006). How to conduct surveys. (3rd ed.). London, UK: Sage Publications Ltd.

Gustavsson, L., \& Sathre, R. (2006). Variability in energy and carbon dioxide balances of wood and concrete building materials. Building and Environment, 41, 940-951.

Hairstans, R., \& Kermani, A. (2007). Structural insulated panels in modern construction. Proceedings of the ICE-Construction materials, 160, 91-94.

Hutton, T., Lloyd, H., \& Singh, J. (1992). The environmental control of timber decay. Structural Survey, 10, 5-20.

IWS (2011). Internet usage in the European Union - EU27. http://www.internetworldstats.com/stats9.htm.

Johnston, D., \& Gibson, S. (2008). Green from the ground up: Sustainable, healthy, and energyefficient home construction. Newton, CT: The Taunton Press.

Jones, B. (2007). Building with straw bales: A practical guide for the UK and Ireland. (2nd ed.). Totnes, UK: Green Books.

Lennon, T., Bullock, M., \& Enjily, V. (2000). The fire resistance of medium-rise timber framed buildings. In Proceedings of the World Conference on Timber Engineering.

Lenzen, M., \& Treloar, G. (2002). Embodied energy in buildings: wood versus concrete -reply to Börjesson and Gustavsson. Energy Policy, 30, 249-255.

Morel, J., Mesbah, A., Oggero, M., \& Walker, P. (2001). Building houses with local materials: Means to drastically reduce the environmental impact of construction. Building and Environment, 36, 1119-1126.

Morley, M. (2000). Building with Structural Insulated Panels (SIPS). Newtown, CT: The Taunton Press, Inc.

ONS (2011). Population estimates for UK, England and Wales, Scotland and Northern Ireland: Mid2010 population estimates. http://www.ons.gov.uk/ons/publications/.

Oppenheim, A. (1992). Questionnaire Design, Interviewing and Attitude Measurement. (2nd ed.). London, UK: Continuum.

Ravetz, J. (2008). State of the stock - what do we know about existing buildings and their future prospects? Energy Policy, 36, 4462-4470.

Schnettler, S. (2009). A structured overview of 50 years of small-world research. Social Networks, 31, $165-178$.

Seyfang, G. (2010). Community action for sustainable housing: Building a low carbon future. Energy Policy, 38, 7624-7633.

Smith, C. J. (2007). High-performance Building Envelopes: High-Performance Straw Bale. Environmental Design and Construction, May, 60-68.

SurveyMonkey (2011). Free online survey software \& questionnaire tool. http://www.surveymonkey.com/.

UK Parliament (2008). Climate Change Act 2008. London, UK: UK Parliament. 


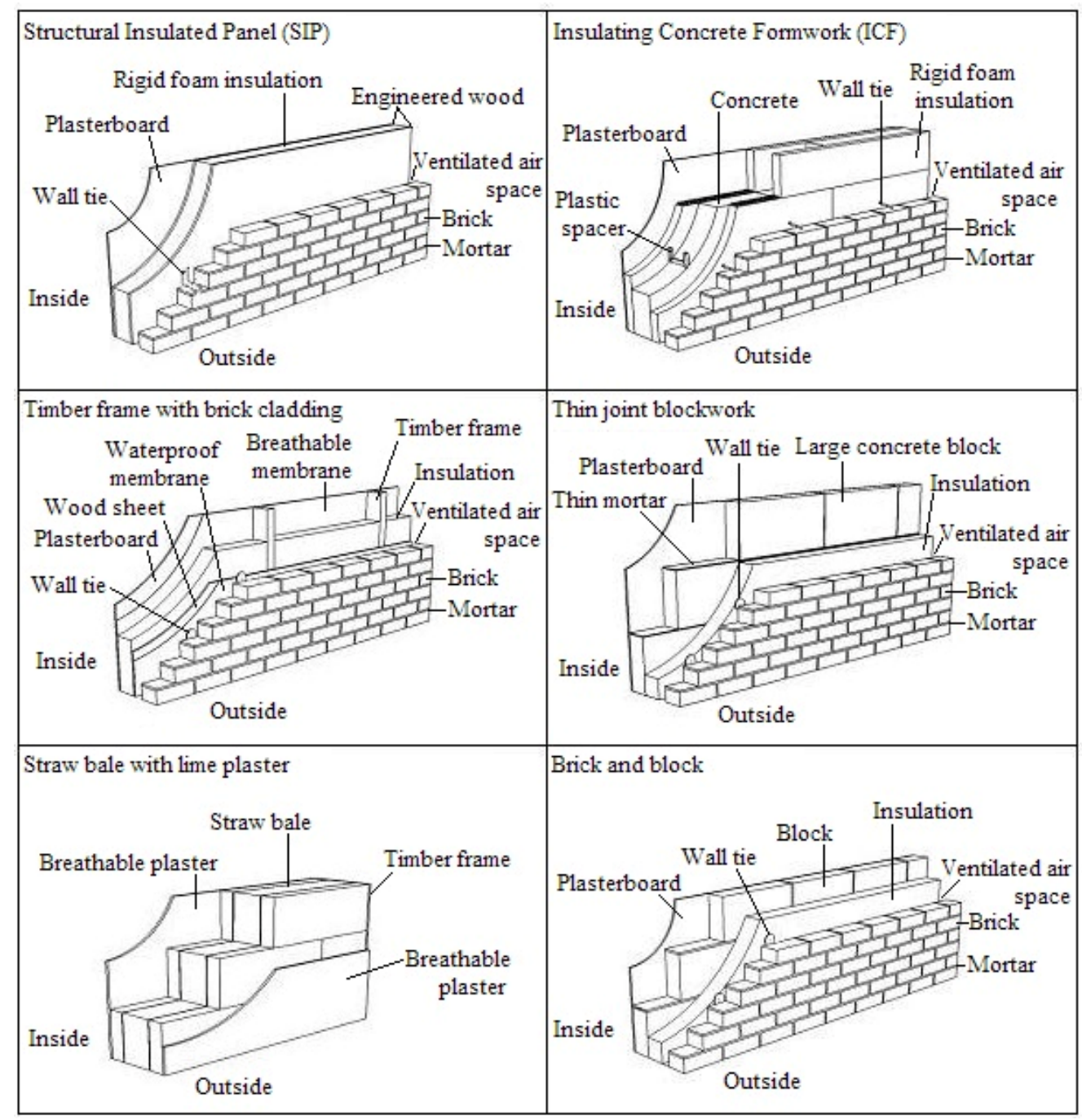

Figure 1: Diagrams showing axonometric views of investigated wall construction types. 


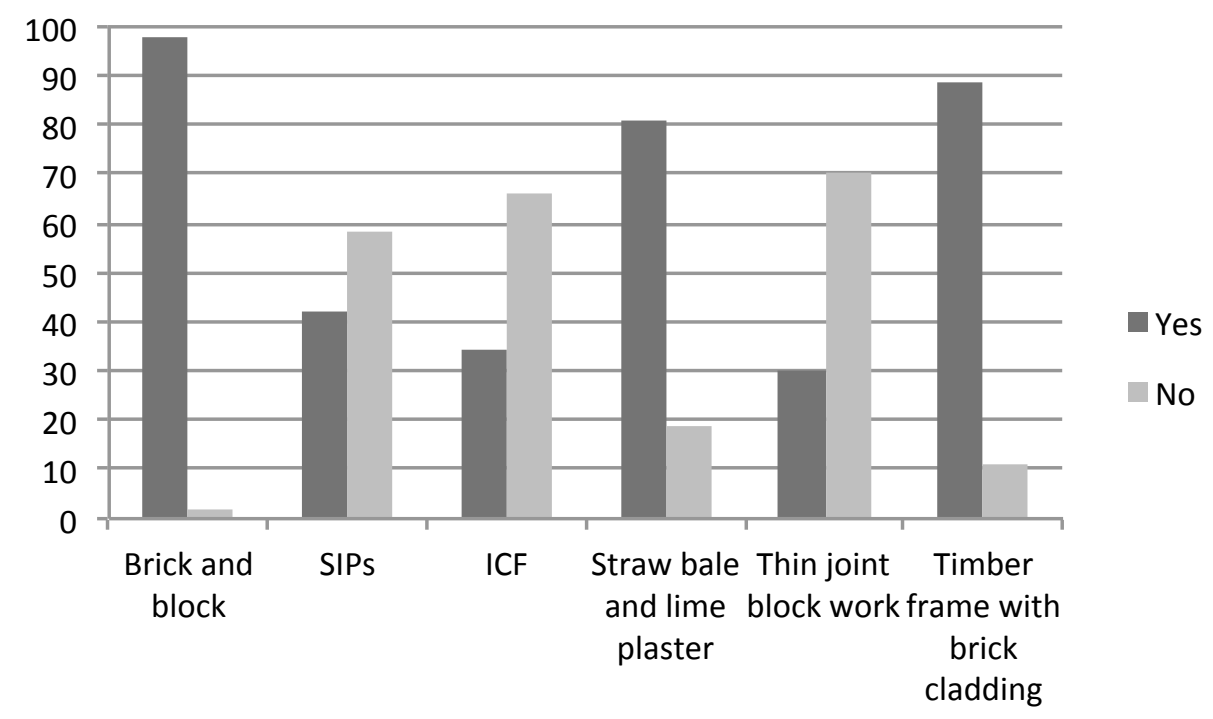

Figure 2: Percentage of respondents who have heard of each construction technique. 
Table 1: Age distribution of respondents and the UK population.

\begin{tabular}{|l|l|l|}
\hline \multirow{2}{*}{ Age range } & \multicolumn{2}{|l|}{ Distribution } \\
\cline { 2 - 3 } & UK & Survey \\
\hline $18-29$ & 19.4 & 18 \\
\hline $30-44$ & 29.2 & 35 \\
\hline $45-59$ & 24.5 & 29 \\
\hline $60-74$ & 17.2 & 16 \\
\hline 75 and over & 9.7 & 2 \\
\hline
\end{tabular}


Table 2: Modal and median importance scores for each characteristic when choosing a house.

\begin{tabular}{|l|l|l|}
\hline Characteristic & Score & Median \\
\hline & Modal & 3 \\
\hline Fire risk & 3 & 5 \\
\hline Price & 5 & 4 \\
\hline Low energy use & 4 & 4 \\
\hline Need for maintenance & 4 & 3 \\
\hline Price of insurance & 3 & 4 \\
\hline Mortgage availability & 5 & 3 \\
\hline Environmental impacts of construction & 3 & \\
\hline
\end{tabular}


Table 3: Rotated component matrix of questionnaire items.

\begin{tabular}{|c|c|c|c|c|}
\hline \multirow[t]{2}{*}{ Item } & \multicolumn{4}{|l|}{ Component } \\
\hline & Environmental & Financial & $\begin{array}{l}\text { Operating } \\
\text { costs }\end{array}$ & Risk \\
\hline Environmental impacts of construction & .861 & - & - & - \\
\hline Low energy use & .831 & - & - & - \\
\hline Mortgage availability & - & .809 & - & - \\
\hline Selling price & - & .784 & - & - \\
\hline Need for maintenance & - & - & .901 & - \\
\hline Fire risk & - & - & - & .753 \\
\hline Cost of insurance & - & - & .540 & .588 \\
\hline
\end{tabular}

